\title{
PROSPECÇÃO DO MERCADO LATINO-AMERICANO DE SOLVENTES VERDES
}

\author{
Daiane dos Santos Padilha \\ SENAI CETIQT \\ Rua Magalhães Castro, 174 - Riachuelo - Rio de Janeiro/RJ \\ daianedspadilha@gmail.com \\ Rinaldo Farias da Luz \\ SENAI CETIQT \\ Rua Magalhães Castro, 174 - Riachuelo - Rio de Janeiro/RJ \\ rluz@cetiqt.senai.br \\ Raquel Massad Cavalcante \\ EQ / UFRJ \\ Av. Athos da Silveira Ramos, 149 - Cidade Universitária - Rio de Janeiro/RJ \\ massad@eq.ufrj.br
}

\section{RESUMO}

No mundo, em especial na América Latina, observa-se um maior interesse em torno da utilização de solventes verdes nas mais diversas aplicações, impulsionada pela busca de alternativas aos solventes orgânicos. Este trabalho recorreu a análise de patentes, artigos científicos e publicações em mídias especializadas para identificar tendências tecnológicas e mercadológicas da síntese e uso de solventes verdes. Como resultado, constatou-se a tendência de crescimento do mercado latino-americano ao longo dos estágios temporais.

Palavra-chave: solventes verdes; América Latina; prospecção tecnológica; química verde; sustentebilidade.

\begin{abstract}
In the world, especially in Latin America, there is a greater interest in the use of green solvents in the most diverse applications, driven by the search for alternatives to organic solvents. This work involved the analysis of patentes, papers and publications in specialized media to identify technological and market trends in the synthesis and use of green solvents. As a result, the growth trend of the Latin American market was noted throughout the temporal stages.
\end{abstract}

Keywords: green solvents; Latin America; technology prospecting; green chemistry; sustainability.

\section{Como Citar:}

PADILHA, Daiane dos Santos; LUZ, Rinaldo Farias da; CAVALCANTE, Raquel Massad. Prospecção do mercado latino-americano de solventes verdes. In: SIMPÓSIO DE 
PESQUISA OPERACIONAL E LOGÍSTICA DA MARINHA, 19., 2019, Rio de Janeiro, RJ. Anais [...]. Rio de Janeiro: Centro de Análises de Sistemas Navais, 2019.

\section{INTRODUÇÃO}

Um dos mais importantes setores da economia brasileira corresponde à indústria química e petroquímica, que está entre as dez maiores do mundo ${ }^{1}$. Segundo documento divulgado pela ABIQUIM ${ }^{\circledR}$ ao final de 2017, o faturamento líquido da indústria química brasileira foi de US\$119,6 bilhões, o que confere ao Brasil o $8^{\circ}$ lugar no ranking mundial ${ }^{2}$.

Dentro deste setor, incluem-se diversos segmentos de produção. Dentre eles, destaca-se o segmento de solventes e diluentes orgânicos compostos, que, na última década, sofreu retração de $40 \%$ do mercado, devido às políticas regulatórias adotadas pela Agência Nacional do Petróleo, Gás Natural e Biocombustíveis (ANP) para impedir a adulteração de combustíveis ${ }^{3}$. Ainda assim, segundo dados divulgados pelo Ministério da Indústria, Comércio Exterior e Serviços, este segmento arrecadou cerca de US\$ 34 milhões em exportações nos últimos 5 anos $^{4}$.

Em um panorama global, este segmento movimentou, somente em 2015, cerca de US\$ 20 bilhões; dados obtidos pela UN Comtrade mostram que, em 2017, os 10 países que mais exportaram solventes no mundo somaram US\$ 1,07 bilhão ${ }^{5}$ A região Ásia-Pacífico representa o maior mercado individual de solventes, seguido pela Europa e América do Norte ${ }^{6}$.

Os participantes do mercado de solventes incluem gigantes químicos globais como a alemã BASF®, a anglo-holandesa Shell ${ }^{\circledR}$, as americanas Eastman Chemical Company ${ }^{\circledR}$ e Exxon Mobil ${ }^{\circledR}$, a belga Solvay ${ }^{\circledR}$ e a sul-africana Sasol ${ }^{\circledR}$, dentre muitas outras. No Brasil, o segmento de solventes é composto por outros gigantes da indústria química nacional, como a Petrobrás ${ }^{\circledR}$, a Braskem ${ }^{\circledR}$ e a Rhodia ${ }^{\circledR}$. Em termos de aplicações, tintas e revestimentos, produtos farmacêuticos e adesivos dominam o consumo global de solventes ${ }^{6}$.

Em termos gerais, os solventes são substâncias que dissolvem um soluto, resultando em uma solução; são, usualmente, derivados do processamento de petróleo, de gás natural e de frações da indústria petroquímica, passíveis de serem utilizados como dissolventes de substâncias sólidas ou líquidas, puras ou em mistura ${ }^{7}$. O segmento de solventes e diluentes orgânicos compostos tem ganhado destaque nos últimos anos, devido a questões que envolvem a crescente demanda por solventes menos agressivos ao meio ambiente, isto é, que acarretem baixa emissão de voláteis (“low VOC”)

A cada ano, mais de vinte milhões de toneladas de resíduos de solventes orgânicos são emitidos para a atmosfera, causando, além de poluição, desperdício desnecessário dos mesmos. Além disso, a exposição prolongada a solventes tem um impacto prejudicial aos seres vivos no geral, danificando principalmente os sistemas respiratório e nervoso ${ }^{9}$.

Deste modo, reduzir o uso dos solventes orgânicos ou substituí-los por outros menos tóxicos é um dos objetivos mais relevantes do segmento, em particular da chamada Química Verde ${ }^{9}$. Apesar de os solventes oriundos de processos petroquímicos ainda apresentarem comparativamente menores $\operatorname{custos}^{10}$, os solventes verdes vêm se tornando uma alternativa viável para substituir os solventes orgânicos e minimizar os impactos socioambientais ${ }^{11}$.

Diante da complexidade deste cenário, um estudo prospectivo se faz necessário. A prospecção tecnológica pode ser definida como um mapeamento de desenvolvimentos científicos e tecnológicos futuros, capazes de influenciar significativamente uma indústria, a economia ou a sociedade e que tem como principal objetivo fornecer subsídios a fim de gerar informações importantes para a tomada de decisões estratégicas ${ }^{12}$.

De maneira geral, não há uma regra ou fórmula exata para metodologias de 
prospecção tecnológica; deve-se desenvolver e definir aquela mais adequada à necessidade em questão, a depender de fatores como a área de conhecimento envolvida e a abrangência do estudo ${ }^{12}$. Uma das ferramentas disponíveis para avaliação de tecnologias e do mercado como um todo é o Technology Roadmap (TRM), ao qual busca reunir em um mesmo documento o estado da arte e os principais avanços tecnológicos de um determinado setor, realizando, desta forma, a projeção das tendências identificadas ao longo de um horizonte temporal definido ${ }^{13}$.

Em função do cenário apresentado, este trabalho busca estudar a ferramenta de prospecção tecnológica, bem como desenvolvê-la de forma a contribuir para a identificação e a discussão de possíveis novas rotas de produção e desenvolvimento de solventes menos poluentes. Este trabalho tem como objetivo geral fornecer um direcionamento para o desenvolvimento tecnológico que os solventes ditos "verdes" podem alcançar durante os próximos anos. A importância deste trabalho se encontra nas questões ambientais, ocupacionais e econômicas relacionadas ao uso de solventes orgânicos convencionais, bem como nas questões tecnológicas que envolvem os solventes alternativos.

Além da enorme quantidade de resíduos de solventes que são despejados na natureza a cada ano, conforme já exposto, solventes orgânicos, principalmente os hidrocarbonetos e os clorados, emitem compostos orgânicos voláteis (VOC), levando, consequentemente, à destruição da camada de ozônio e a formação de neblina fotoquímica ${ }^{14}$. Devido a essas questões, descobertas por volta da década de 1980, diversas restrições quanto ao uso e a comercialização destes solventes entraram em vigor desde então.

A exposição prolongada aos solventes orgânicos prejudica o funcionamento de órgãos vitais e pode levar ao desenvolvimento de uma série de doenças; o tetracloreto de carbono e o clorofórmio são hepatotóxicos, enquanto que o uso prolongado de éteres de glicol e solventes clorados causam insuficiência renal. Em casos mais graves, lidar com alguns tipos de solventes, como os hidrocarbonetos halogenados e os destilados de petróleo, pode levar à necrose tubular torácica ${ }^{9}$.

Economicamente, solvente orgânicos continuam sendo mais baratos que alternativas mais sustentáveis e limpas. Porém, segundo relatório divulgado em 2010 pela British Petroleum ${ }^{10}$, assumindo que o consumo humano de derivados do petróleo continue a crescer no ritmo atual, a quantidade de petróleo disponível em todas as jazidas do mundo é o suficiente apenas para os próximos 46 anos. Frente a esta realidade, o desenvolvimento de rotas alternativas às tradicionais torna-se indispensável.

Desta maneira, um estudo de prospecção se faz necessário, a fim de que rotas alternativas às tradicionais sejam indicadas de forma clara e objetiva aos gestores e tomadores de decisão. Este trabalho delimita-se em estudar e tratar as informações referentes às questões tecnológicas da produção e uso dos solventes ditos “verdes”, principalmente da água, dos líquidos iônicos e dos fluídos supercríticos. Além disso, o estudo terá como ênfase apenas o mercado latino-americano, no que se refere às bases de dados de patentes (Latipat) e de artigos científicos (Scielo) utilizadas na pesquisa.

\section{METODOLOGIA}

A metodologia utilizada neste trabalho de prospecção tecnológica é adaptada de metodologias já consagradas nos meios acadêmicos ${ }^{15,16,17}$ e decorre por meio de três etapas prospectivas: etapa pré-prospectiva, etapa prospectiva e etapa pós prospectiva.

A primeira etapa consiste na análise fundamental e preliminar do objeto de estudo. Baseia-se em uma pesquisa básica acerca do tema de estudo para possibilitar um levantamento prévio sobre assuntos, campos e fontes referentes ao tema estudado. Nesta 
fase, utilizou-se o buscador Google ${ }^{\circledR}$ acerca de artigos de revisão, artigos de pesquisa e notícias, uma vez que esta ferramenta retorna resultados de diversas fontes de notícias encontradas pela internet. Desta forma, são definidos o horizonte temporal, o nível de detalhes necessários à ferramenta e as taxonomias utilizadas na etapa seguinte $\mathrm{e}^{15,16,17}$.

Com as taxonomias iniciais definidas na etapa anterior, pôde-se dar início a segunda etapa, que corresponde à etapa de prospecção tecnológica. Esta fase se baseou na leitura e organização de notícias, patentes e artigos científicos. Após a escolha das palavras-chave, foi realizada a escolha dos bancos de dados a serem utilizados na pesquisa. Para se obter uma visão do mercado latino-americano de solventes verdes, foi escolhido a Latipat como banco de dados de patentes e a Scielo como banco de dados de artigos científicos. Dessa análise identificam-se os fatores tidos como os requisitos críticos, alvos, áreas tecnológicas e metas do objeto de prospecção $0^{15,16,17}$.

Após realizar esta busca orientada, é preciso analisar os resultados obtidos, que por sua vez também requer uma sistematização para que se possa extrair toda informação necessária. Esta análise acontece organizando as informações em 3 níveis ${ }^{15,16,17}$ :

- Nível macro: compreende as informações mais imediatas dos documentos, como o número da patente, o título, o resumo (abstract), o ano, o solicitante (no caso das patentes) ou a instituição (no caso dos documentos acadêmicos), e o país, informações posteriormente adaptadas para os outros tipos de documentos;

- Nível meso: aqui, foram classificados os documentos encontrados com base nas taxonomias (água, fluído supercrítico e líquido iônico) observadas tanto em patentes quantos em artigos e notícias;

- Nível micro: nesta etapa, foram separados os documentos com base nas taxonomias que se englobavam dentro das definidas para a análise meso, isto é, taxonomias específicas de cada categoria.

Ao final da etapa prospectiva, devem-se organizar as informações que estão sendo trabalhadas por meio de uma planilha. A partir desta avaliação prévia, foi possível ter uma base sólida sobre o tema para prosseguir com a prospecção. A terceira etapa compreende a elaboração do roadmap ${ }^{15}$ em si. Esta última etapa não está contemplada neste trabalho.

Neste trabalho, ocorre uma adaptação à metodologia usualmente aplicada neste tipo de prospecção. Normalmente, utilizam-se notícias, anais e catálogos de empresas para compor o estágio atual, patentes concedidas para o curto prazo, patentes depositadas para o médio prazo e artigos científicos para o longo prazo. Como foi constatado que, na base de patentes Latipat, não há a informação de concessão das patentes, foi levado em consideração apenas a data de publicação das mesmas. Além disso, tanto na base Latipat quanto na Scielo, não houve delimitação de tempo nas buscas, ou seja, foram recuperados todos os documentos disponíveis referentes às taxonomias utilizadas. Desta forma, a mais antiga patente recuperada na pesquisa data de 1989, assim como o mais antigo artigo científico data de 1996, havendo assim a necessidade de se adaptar a metodologia para este caso.

Dessa maneira, a construção dos estágios temporais deu-se da seguinte forma: o estágio atual corresponde às notícias e informações disponíveis nos sites das empresas e de associações, bem como às patentes publicadas antes de 1999; o curto prazo corresponde às patentes publicadas entre 1999 e 2008 e aos artigos científicos publicados antes de 1999; o médio prazo corresponde às patentes publicadas entre 2009 e 2018 e aos artigos científicos publicados entre 1999 e 2008; por fim, o longo prazo corresponde aos artigos científicos publicados entre 2009 e 2018. 


\section{RESULTADOS E DISCUSSÕES}

Ao pesquisar a tecnologia de solventes verdes, foram identificadas três classes principais: água, líquidos iônicos e fluídos supercríticos. Alguns autores também consideram como solventes verdes aqueles cuja produção ocorre de forma mais limpa; portanto, a terminologia geral "solvente verde" também foi considerada. Assim, a Tabela 1 mostra as palavras-chave escolhidas, o número de resultados obtidos com a busca e os resultados considerados relevantes para o tema do trabalho.

Tabela 1 - Total de documentos encontrados nas bases de dados e considerados relevantes

\begin{tabular}{|c|c|c|c|c|}
\hline Palavras Chave & $\begin{array}{c}\text { Base de } \\
\text { Dados } \\
\end{array}$ & $\begin{array}{c}\text { Tipo de } \\
\text { Documento }\end{array}$ & $\begin{array}{l}\text { Documentos } \\
\text { Encontrados }\end{array}$ & $\begin{array}{c}\text { Documentos } \\
\text { Relevantes }\end{array}$ \\
\hline $\begin{array}{l}\text { solvent* AND neoteric*; fluid* } \\
\text { AND supercritic* AND } \\
\text { solvent*; liquid* AND } \\
\text { supercritic* AND solvent*; gas* } \\
\text { AND supercritic* AND }\end{array}$ & Latipat & Patentes & 372 & 153 \\
\hline $\begin{array}{l}\text { solvent*; fluid* AND ionic* } \\
\text { AND solvent*; liquid* AND } \\
\text { ionic* AND solvent*; "water as } \\
\text { solvent*" OR "agua como } \\
\text { solvent*"; "water-based } \\
\text { solvent*" OR "solvent* a base } \\
\text { de agua"; "base al agua"; green* } \\
\text { AND solvent* OR solvent* } \\
\text { AND verde* }\end{array}$ & Scielo & $\begin{array}{c}\text { Artigos } \\
\text { Científicos }\end{array}$ & 236 & 145 \\
\hline
\end{tabular}

Fonte: Autoria própria (2018)

A partir dos dados recuperados nas bases de dados, bem como após a análise dos documentos considerados relevantes, seguindo a metodologia proposta, avaliou-se o número de documentos publicados por ano, gerando a Figura 1.

Figura 1 - Número de documentos resgatados por ano.

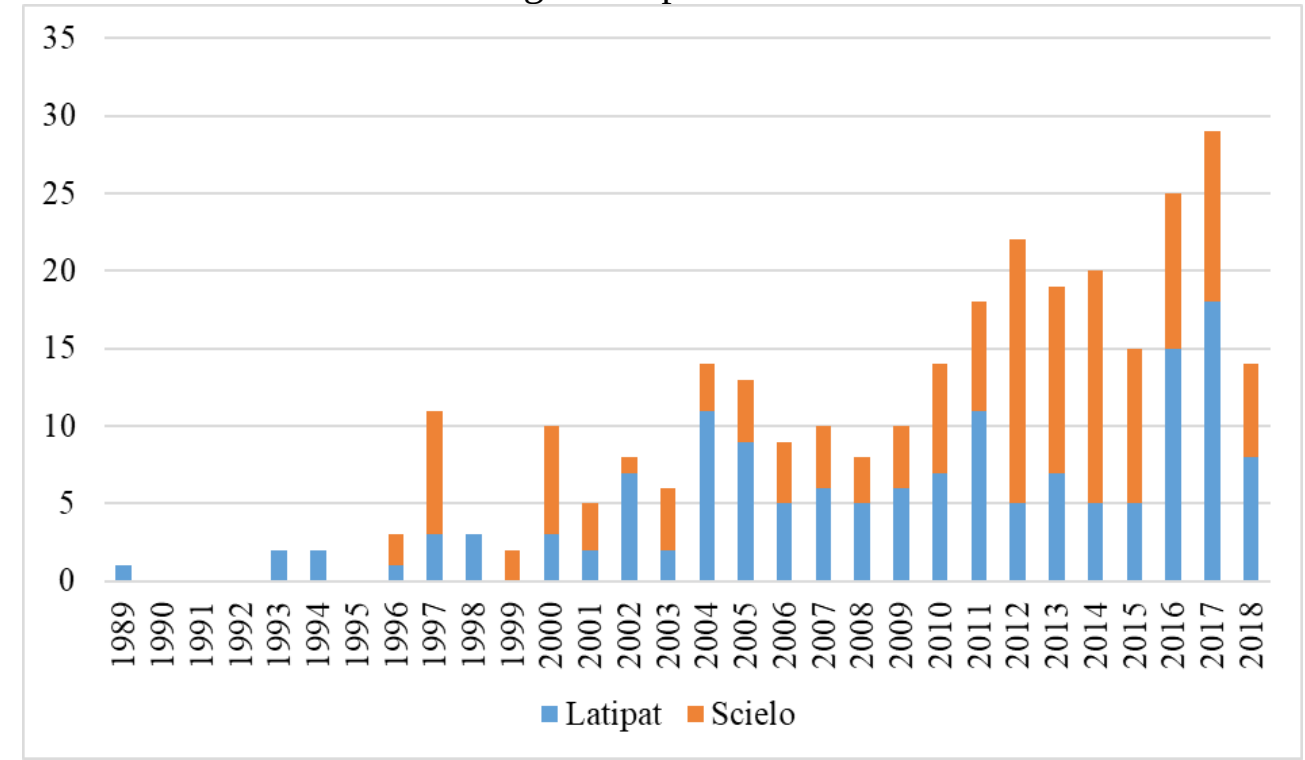

Fonte: Autoria própria (2018) 
Analisando o gráfico da Figura 1, é possível observar que a tecnologia dos solventes verdes vem crescendo dentro do segmento químico latino-americano ao longo dos anos, havendo ainda uma forte tendência ao patenteamento de invenções envolvendo este tipo de tecnologia nos anos de 2004 e 2011, e, destacadamente, nos últimos dois anos, em 2016 e 2017. Levando em consideração que, de acordo com o que foi explicado na Metodologia, as patentes publicadas entre 1999 e 2008 correspondem ao estágio temporal de curto prazo e que as que foram publicadas entre 2009 e 2018, ao estágio de médio prazo, isto indica que possivelmente haverá um grande interesse por parte da indústria local, bem como por empresas multinacionais atuantes no mercado latino-americano, por solventes mais limpos a curto e médio prazo, este último principalmente.

A Figura 1 mostra ainda que no período de 2012 a 2014, o número de publicações de artigos científicos que envolvam de alguma forma solventes verdes duplicou em comparação aos 10 anos anteriores. Ao comparar com o número de patentes por ano, é possível observar que o maior número de depósitos ocorreu no período de 2016 e 2017, podendo assim concluir que, em linhas gerais, é evidente que houve um maior interesse por esta tecnologia na década de 2010. Este interesse pode estar relacionado a uma maior preocupação por parte da indústria em cumprir exigências governamentais, principalmente quanto à restrição do uso de produtos químicos nocivos à saúde humana e ao meio ambiente, bem como a incentivos de conferências realizadas recentemente, como a Rio +20 .

A porcentagem de documentos publicados também foi analisada, levando em consideração a instituição de origem do inventor ou autor, se pertencer à América Latina, a outras localidades ou a associações entre instituições locais e estrangeiras. Em relação às patentes, $74 \%$ de toda a tecnologia patenteada em países latino-americanos foram inventadas por empresas multinacionais que atuam no mercado latino-americano, enquanto que os outros $26 \%$ pertencem a empresas locais. No geral, empresas buscam o patenteamento em diversos países (via Patent Cooperation Treaty - PCT) a fim de que esta tecnologia possa ser explorada apenas por elas mesmas, detentoras da invenção. Tais resultados indicam que estas empresas possuem grande interesse em utilizar e desenvolver este tipo de tecnologia em países emergentes.

Já em relação aos artigos científicos, a grande maioria das pesquisas envolvendo solventes verdes, cerca de 68\%, foram realizadas por instituições latino-americanas, enquanto que $25 \%$ destas foram realizadas por instituições de outras localidades e uma pequena parcela, por volta de $8 \%$, se deram através de parcerias entre instituições da América Latina e de outros continentes. Isso mostra que parte dos artigos analisados foram publicados por instituições estrangeiras que tem interesse em divulgar seus estudos dentro do meio acadêmico latino-americano, a fim de buscar parcerias internacionais. Vale ressaltar que estas instituições podem se tratar tanto de universidades quanto de centros de pesquisa.

Foram identificados seis clusters, que representam os seguintes mercados: tintas, representado pelas empresas Suvinil ${ }^{\circledR}$, Coral ${ }^{\circledR}$ e Sherwin Williams ${ }^{\circledR}$, dentre outras; adesivos e selantes, representado por empresas como a Dow ${ }^{\circledR}$, a $3 \mathrm{M} \AA$ e a Sparlack ${ }^{\circledR}$, dentre outras; pigmentos, representado pelas empresas Mimaki ${ }^{\circledR}$, Aranjuez ${ }^{\circledR}$, Vivacor ${ }^{\circledR}$ e Roland ${ }^{\circledR}$; desengraxante industrial, formado pela $\mathrm{NCH}{ }^{\circledR}$ e demais empresas; resinas, representado pelas nacionais ArtSol ${ }^{\circledR}$, Redelease ${ }^{\circledR}$ e Hydronorth ${ }^{\circledR}$; e o mercado de equipamentos, representado pelas empresas Jasco do Brasil ${ }^{\circledR}$, Air Products ${ }^{\circledR}$ e Lewa ${ }^{\circledR}$. Empresas como a Oxiteno ${ }^{\circledR}$ e a Rhodia ${ }^{\circledR}$ vêm desenvolvendo tecnologias para a síntese de solventes verdes, enquanto que universidades como o Centro Universitário FEI têm utilizado o líquido iônico 1-butil-3-metil-imidazólio hexafluorfostato em procedimentos laboratoriais.

Empresas como a AstraZeneca ${ }^{\circledR}$, Lavipharm ${ }^{\circledR}$, Dompé ${ }^{\circledR}$ e Ethypharm ${ }^{\circledR}$ apresentaram patentes relacionadas ao uso de fluído supercrítico na produção de fármacos, 
tanto em processos de extração quanto de solubilização. Também foram encontradas patentes envolvendo o uso de água como meio solubilizante em diferentes aplicações, pertencentes à empresas como a SCJohnson ${ }^{\circledR}$, para a produção de produtos de limpeza, a Monsanto ${ }^{\circledR}$, aplicado na emulsão de defensivos agrícolas, e a Shell ${ }^{\circledR}$, na síntese de ésteres. Em relação a produção e uso de líquidos iônicos, foram encontradas patentes das alemãs Degussa ${ }^{\circledR}$, aplicado na síntese de aromáticos, e Bayer ${ }^{\circledR}$, que trata da produção do 1,3dialquil-imidazol e de sua aplicação na síntese de oligômeros de isocianatos. Representando a América Latina, destaca-se a Boticário ${ }^{\circledR}$, detentora de uma patente que utiliza água na produção de cosmético com aplicação capilar, e a Portkoll@ ${ }^{\circledR}$, que patenteou uma invenção que faz uso de água em revestimentos epóxi. Também destacam-se a Universidade Estadual de Campinas (UNICAMP), que patenteou uma invenção que faz uso de fluído supercrítico como meio de extração para produção de fármacos, e a Petrobrás, detentora de uma patente da síntese do 1,3-dialquil-imidazol livre de halogenetos.

Uma série de patentes foi depositada pela Unilever®, utilizando água como solvente na síntese de ácido amidocarboxílico e para a produção de cosméticos. Ainda utilizando água como solvente, é possível observar tanto a Reckitt Benckiser® quanto a Rhodia ${ }^{\circledR}$ utilizando água na produção de produtos de limpeza. Quanto a síntese e utilização de líquidos iônicos como solvente, pode-se citar como exemplos o Instituto Mexicano del Petroleo ${ }^{\circledR}$, que patenteou processos que utilizam líquidos iônicos para tratar frações de nafta e reduzir a viscosidade do petróleo cru, e a Chevron ${ }^{\circledR}$, que em sua patente utiliza líquido iônico como catalisador e propõe um processo para regenerá-lo; também foram encontradas patentes e artigos publicados por diversas universidades e centros de pesquisa a respeito da síntese e do uso de líquidos iônicos, como a parceria entre UFRGS e a UNB, bem como a argentina Consejo Nacional de Investigaciones Científicas y Técnicas (CONICET) e as brasileiras Universidade Estadual de Campinas (UNICAMP) e Universidade Federal de Pelotas (UFPEL). Fluídos supercríticos são utilizados como solventes em inventos pertencentes a Standard Alcohol Company of America ${ }^{\circledR}$, para a produção de álcool a partir de gás de síntese, e a $P \& G \AA$, que utiliza dióxido de carbono e propano em estados supercríticos no tratamento de partículas poliméricas.

Por último, Universidades e instituições chinesas e iranianas, cujos trabalhos foram publicados em revistas latino-americanas também foram avaliadas. Estas obras foram mantidas no estudo, pois entende-se que estas instituições asiáticas têm grande interesse em divulgar seus estudos acerca do tema dentro do meio acadêmico latino-americano, a fim de que possam ser estabelecidas futuras oportunidades de parcerias acadêmicas e mercadológicas entre os dois continentes. Assim, destacam-se trabalhos realizados pela Islamic Azad University, que tratam da síntese e aplicação de líquidos iônico na recuperação de metais, bem como da aplicação de fluido supercrítico para extração de óleo de canola, e pelas chinesas Wuhan University, que utiliza líquido iônico como aditivo em reações catalisadas por (L)-prolina, e China Agricultural University, que utilizou o líquido iônico (1hexyl-3-methylimidazolium hexafluorophosphate) para determinar o teor de pesticida presente na água e no solo. Em se tratando de América Latina, destacam-se os artigos publicados pelas colombianas Universidad Nacional de Colombia, estudando os efeitos antioxidantes do araçá-boi utilizando água como solvente para a extração do princípio ativo, e Universidad de Córdoba, que estudou o efeito das interações moleculares entre o líquido iônico (1-Butyl-3-methyl imidazolium trifluoromethanesulfonate) e água. A partir destes estudos, é possível observar também a aplicação de novos líquidos iônicos, diferentes dos que já existem no mercado atualmente, como os derivados do (1-Ethyl-3methylimidazolium), produzidos e utilizados pela BASF®.

A partir dos dados gerados através das análises dos artigos, foram derados dados prospectivos do cenário latino-americano de solventes verdes e possibilitar uma melhor 
observação de suas tendências futuras. Considerando a localização geográfica dos documentos utilizados na investigação, foi gerado o gráfico da Figura 2.

Figura 2 - Prospecção tecnológica por classe de solvente

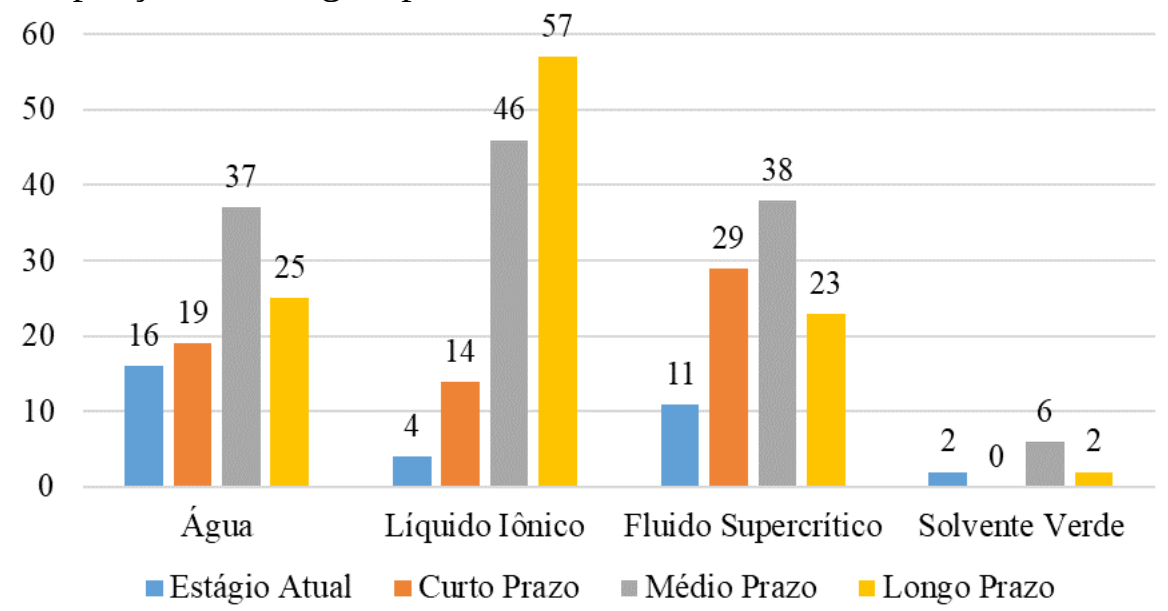

Fonte: Autoria própria (2018)

De acordo com o gráfico da Figura 2, em relação ao uso tanto de água quanto de fluídos supercríticos como solventes, houve crescimento até a visão a médio prazo; a longo prazo, observou-se uma queda no uso dessa tecnologia. Já ao se observar as tendências de produção e uso de líquidos iônicos, houve crescimentos por todos os estágios temporais, o que indica grandes chances de crescimento desta tecnologia nos próximos anos, corroborando com o que já foi explicado anteriormente. Já os solventes verdes propriamente ditos se mostram uma tecnologia estagnada, o que indica que ou não há interesse por parte da indústria e das instituições de pesquisa em desenvolver este tipo de tecnologia ou os materiais que compõem a classe de solventes verdes não são tratados com a devida terminologia, havendo assim dispersão de dados.

Em relação aos objetivos dos solventes nos processos químicos, mostra-se que grande parte dos documentos que fazem uso de solventes alternativos destinam este tipo de material às mais diversas aplicações industriais. Isso se repete por todos os estágios temporais, enquanto que uma pequena parcela destes trata de síntese de líquidos iônicos e uma outra trata de equipamentos destinados ao uso de solventes verdes. Já em relação às aplicações, para melhor visualizar os gráficos de tendência, foram gerados dois gráficos, um com as aplicações consideradas mais relevantes (Figura 3) e outro com as demais aplicações (Figura 4), conforme seguem. 
Figura 3 - Prospecção tecnológica por aplicações mais relevantes

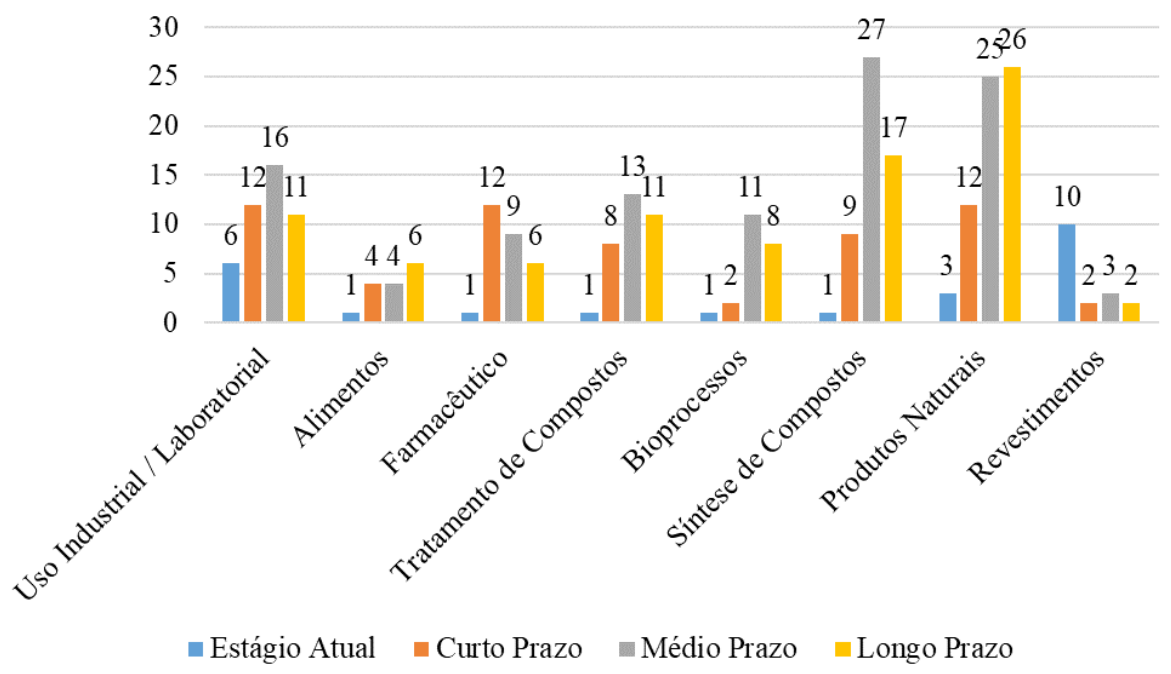

Fonte: Autoria própria (2018)

A Figura 3 mostra que, dentro das aplicações mais relevantes, observou-se que há uma forte tendência de aplicação dessa tecnologia na extração de produtos naturais, com crescimentos consideráveis em todos os estágios temporais. Com relação à aplicação de solventes verdes na síntese de compostos, houve crescimento até o médio prazo, ocorrendo uma queda no longo prazo; o mesmo ocorreu nas seguintes aplicações: uso industrial/laboratorial, tratamento de compostos e bioprocessos. Isso pode ser justificável tanto pelo número de documentos considerados em cada estágio temporal, conforme já foi mencionado, quanto pela própria estagnação da implantação desta tecnologia nestes setores. O setor de alimentos apresentou leve crescimento ao longo dos estágios temporais, enquanto que o setor farmacêutico apresentou crescimento a curto prazo e sucessivas quedas a médio e longo prazos. Surpreendentemente, o setor de revestimentos, que no estágio atual se apresenta como o setor que mais aplica solventes verdes, não apresentou muitos documentos que justificassem o uso dessa tecnologia nos três outros estágios temporais, o que demonstra que possivelmente esta tecnologia já esteja consolidada dentro do setor e/ou não há interesse em desenvolver novas aplicações de solventes verdes. 
Figura 4 - Prospecção tecnológica por outras aplicações

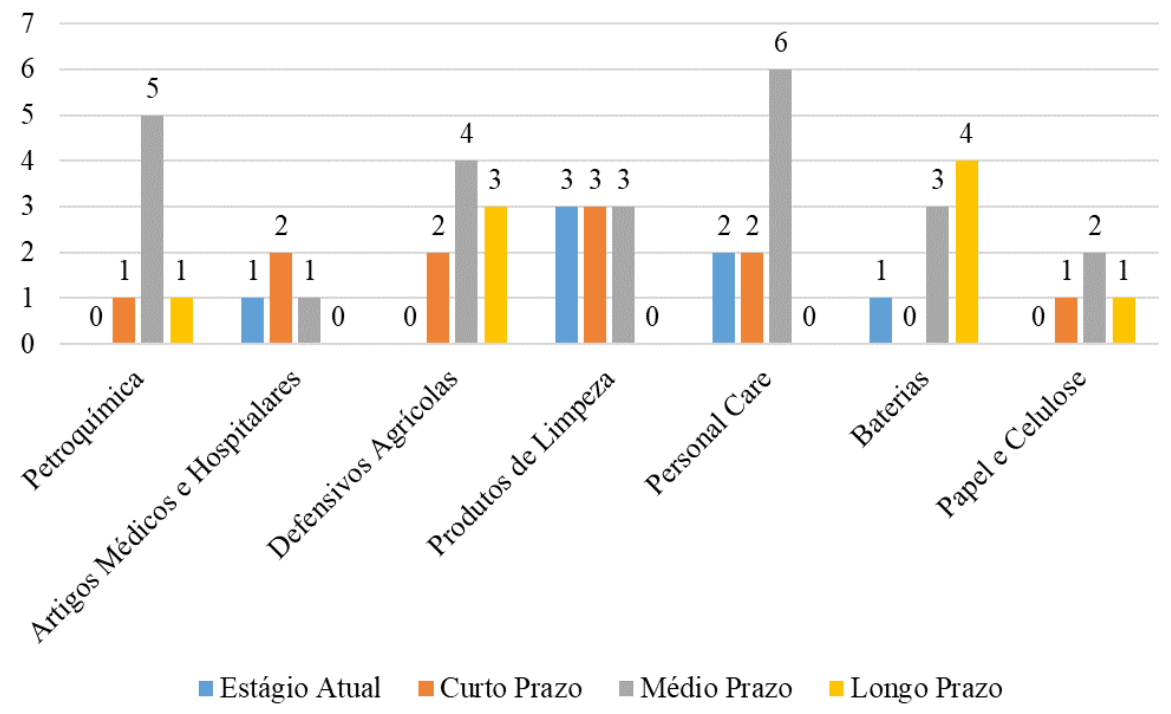

Fonte: Autoria própria (2018)

Na Figura 4, que trata das outras aplicações de solventes verdes consideradas neste trabalho, destacam-se os setores de personal care e de baterias, que apresentaram crescimento ao longo dos estágios temporais, apesar de o setor de personal care não apresentar documentos que comprovem a utilização destes solventes a longo prazo e o de baterias, a curto prazo. Quanto às demais aplicações, segue breve análise: o setor petroquímico apresentou forte crescimento a médio prazo, porém volta a decair a longo prazo; o de produtos de limpeza sofreu estagnação desde o estágio atual até o médio prazo, não apresentando aplicações a longo prazo; o de defensivos agrícolas sofreu crescimento até o estágio a médio prazo, sofrendo leve queda a longo prazo; tanto os setores de artigos médicos e hospitalares e de papel e celulose tiveram poucas representações aos longo dos estágios temporais, apresentando estagnação.

5.

Quanto à função que estes solventes desempenham, foi gerado o gráfico da Figura

Figura 5 - Prospecção tecnológica por função

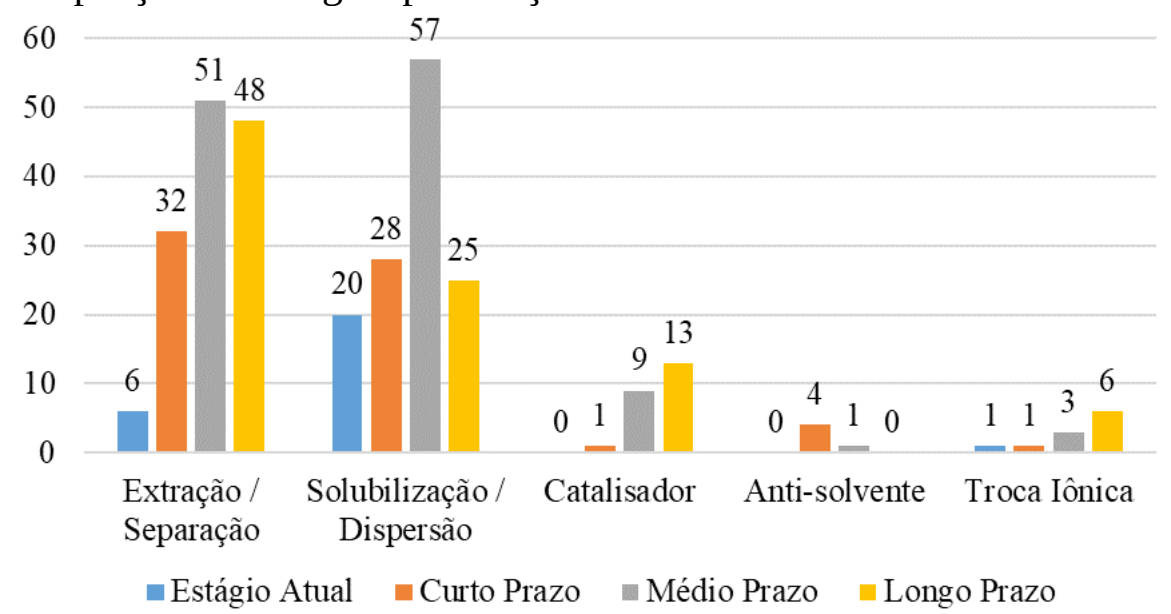


Fonte: Autoria própria (2018)

Pela Figura 5, ao observar este gráfico como um todo, percebe-se uma grande aplicabilidade de solventes alternativos na extração/separação e na solubilização/dispersão. Observando apenas as colunas referentes à extração/separação, nota-se que houve forte crescimento desde o estágio atual até a visão a médio prazo, sofrendo estagnação a partir do longo prazo. Já em relação a função de solubilização/dispersão, houve crescimento até o médio prazo e uma queda significativa no longo prazo, ficando abaixo até mesmo do que é mostrado a curto prazo. Em relação às demais funções desempenhadas por estes solventes, segue análise: tanto a função de catalisador quanto a de troca iônica tiveram crescimento ao longo dos estágios temporais, enquanto que a função de anti-solvente teve crescimento apenas a curto prazo, sofrendo queda a partir do médio prazo.

Por fim, considerando a localização dos documentos utilizados na pesquisa, gerouse o gráfico da Figura 6.

Figura 6 - Prospecção tecnológica por localização

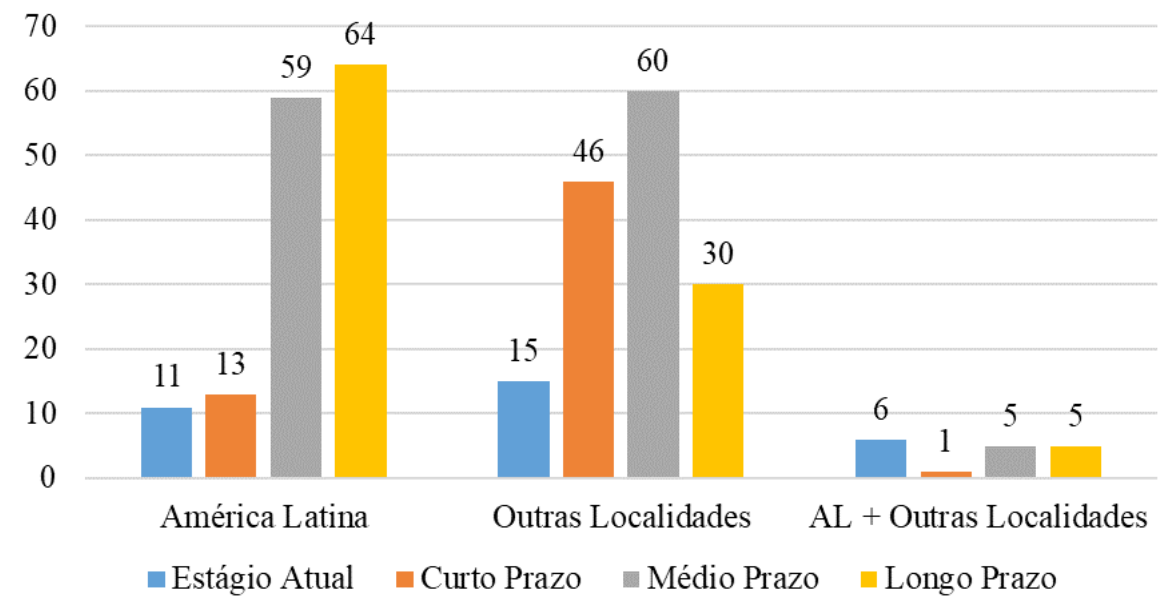

Fonte: Autoria própria (2018)

Analisando o gráfico da Figura 6, percebe-se que há uma forte tendência de crescimento dessa tecnologia dentro da América Latina; a longo prazo, esta apresenta-se ainda maior que as tendências de outras localidades, que por sua vez sofreu uma queda no número de documentos que envolvem solventes verdes de alguma forma neste estágio temporal, apesar de apresentar crescimento ao longo dos demais estágios. Já ao observar as parcerias entre empresas e instituições latino-americanas e de outras localidades, observa-se uma certa estagnação nas pesquisas realizadas em conjunto.

\section{CONCLUSÃO}

Ao pesquisar sobre a tecnologia de solventes verdes, identificaram-se três classes principais: água, líquidos iônicos e fluidos supercríticos. Alguns autores também consideram como solventes verdes aqueles cuja produção se dê de forma mais limpa, portanto a terminologia geral "solvente verde" também foi considerado neste trabalho e observou-se que há poucas pesquisas acerca deste grupo de substâncias. O que foi observado é que, na maioria dos documentos estudados, nas três classes predominantes não são tratadas com esta terminologia, porém o processo em que estão inseridos se enquadra dentro do que é considerado Química Verde. 
Através da ferramenta de prospecção tecnológica, foi possível analisar as tendências de mercado e tecnologia referentes aos setores que produzem e fazem uso de solventes verdes, principalmente no que se refere às diferentes classes de solvente, suas aplicações e funções dentro da indústria ou das instituições de pesquisa, bem como onde estas empresas estão atuando, se dentro da América Latina ou em outras localidades mundiais.

Assim, em relação ao estágio atual do mercado latino-americano de solventes verdes, a maior aplicação destas substâncias atualmente é no setor de revestimentos, como tintas, pigmentos, resinas, adesivos e selantes. A curto prazo, os setores de produtos naturais e farmacêuticos, bem como a utilização de solventes verdes em equipamentos industriais e laboratoriais, são os que mais irão empregar esse tipo de solvente, principalmente em processos de extração. A médio prazo, solventes verdes continuarão a ter grande aplicabilidade na extração de produtos naturais, bem como na síntese de compostos, tendência essa que se estenderá para o cenário a longo prazo. Em todos os cenários, foi possível acompanhar também a tendência de crescimento do mercado latino-americano na síntese e aplicação de solventes verdes.

Dessa forma, conclui-se que a tendência mundial é que todos os setores produtivos busquem alternativas mais limpas e sustentáveis de produção e desenvolvimento; em se tratando de América Latina, esta possui um grande potencial de aplicação e de desenvolvimento de novas tecnologias verdes.

\section{REFERÊNCIAS BIBLIOGRÁFICAS}

PANASSOL, Marcos. Indústria química no Brasil: Um panorama do setor. PwC, 2013. Disponível em: <https://www.pwc.com.br/pt/publicacoes/setores-atividade/assets/quimicopetroquimico/2013/pwc-chemicals-port-13.pdf>. Acesso em: 11 ago. 2018.

ABIQUIM. O DESEMPENHO DA INDÚSTRIA QUÍMICA EM 2017. Disponível em: $<$ https://abiquim.org.br/uploads/guias_estudos/desempenho_industria_quimica_2017.pdf>. Acesso em: 11 ago. 2018.

PEREZ, Eduardo. NEGÓCIO SOLVENTES: Fórum ANP - Solventes. Braskem, 2015. Disponível em: <www.anp.gov.br/?dw=78379>. Acesso em: 11 ago. 2018.

Comex Stat. Ministério da Indústria, Comércio Exterior e Serviços: 2018. Disponível em: <http://comexstat.mdic.gov.br/pt/home>. Acesso em: 11 ago. 2018.

UN Comtrade. United Nations: 2018. Disponível em: <https://comtrade.un.org/data/> . Acesso em: 12 ago. 2018.

SALGARKAR, Rohan. Players in the solvent market are moving forward with a focused approach to remain competitive. 2017. Disponível em:

<https://www.marketsandmarkets.com/ResearchInsight/solvent.asp>. Acesso em: 12 ago. 2018.

Agência Nacional do Petróleo, Gás Natural e Biocombustíveis (ANP). Solventes. Disponível em: <http://www.anp.gov.br/gas-natural/solventes>. Acesso em: 13 ago. 2018.

ALMEIDA, Hamilton. Solventes: Alternativas verdes se consolidam no mercado de tintas. 2011. Disponível em: <https://www.quimica.com.br/solventes-alternativas-verdes-seconsolidam-no-mercado-de-tintas/>. Acesso em: 11 ago. 2018.

TARCZYKOWSKA, Agata. Green solvents. Journal Of Education, Health And Sport, Bydgoszcz, v. 9, n. 7, p.224-232, jul. 2017. Disponível em: 
<https://www.researchgate.net/publication/319871931_Green_solvents>. Acesso em: 07 ago. 2018.

NORRIS, Benjamin; RUSSELL, Sarah; KITCHEN, Emmett; MCBRIDE, Ryley. Green Organic Solvents. Department of Chemistry, Frostburg State University. Disponível em: <https://www.frostburg.edu/dept/chem/research/green-solvents/>. Acesso em: 07 ago. 2018.

TARGUETA, Juliana. SOLVENTES VERDES. 2017. Disponível em: <https://betaeq.com.br/index.php/2017/07/31/solventes-verdes/>. Acesso em: 09 maio 2018.

LUSTOSA, Rafael; PRADO, Vinicius. 9 Técnicas utilizadas em prospecção tecnológica. Belo Horizonte: Biominas, 2017. Disponível em: <http://biominas.org.br/downloads/e-book9-tecnicas-utilizadas-em-prospeccao-tecnologica/>. Acesso em: 14 abr. 2018.

LOUREIRO, Aline Marta Vasconcelos. O EMPREGO DO MÉTODO TECHNOLOGY ROADMAPPING EM ADESIVOS E SELANTES APLICADOS À CONSTRUÇÃO CIVIL. 331 f. Tese (Doutorado) - Curso de Tecnologia de Processos Químicos e Bioquímicos, Escola de Química, Universidade Federal do Rio de Janeiro (UFRJ/EQ), Rio de Janeiro, 2010.

GARBELOTTO, Paulo (Org.). Solventes Industriais: seleção, formulação e aplicação. São Paulo: Blucher, 2007. 397 p.

BORSCHIVER, Suzana; SILVA, Andrezza Lemos Rangel da. Technology Roadmap: Planejamento estratégico para alinhar mercado-produto-tecnologia. Rio de Janeiro: Editora Interciência, 2016. 110 p.

COELHO, José Antonio Farias; BOTELHO JUNIOR, Sergio; TAHIM, Elda Fontinele. Roadmap tecnológico: um estudo preliminar. Revista Eletrônica de Ciência Administrativa, [s.l.], v. 11, n. 2, p.168-177, 15 nov. 2012. IBEPES (Instituto Brasileiro de Estudos e Pesquisas Sociais).

COUTINHO, Paulo; BOMTEMPO, José Vitor. Roadmap tecnológico em matérias-primas renováveis: uma base para a construção de políticas e estratégias no Brasil. Química Nova, [s.l.], v. 34, n. 5, p.910-916, 2011. FapUNIFESP (SciELO). http://dx.doi.org/10.1590/s010040422011000500032. 